\title{
Anakinra and etanercept prevent embryo loss in pregnant nonobese diabetic mice
}

\author{
Jing Wang ${ }^{*}$, Fan $\mathrm{Wu}^{1,}{ }^{1}$, Qingzhen Xie ${ }^{*}$, Xiaorui Liu ${ }^{1}$, Fuju Tian ${ }^{1}$, Wangming Xu and Jing Yang \\ Reproductive Medicine Center, Renmin Hospital of Wuhan University, Wuhan 430060, China and \\ ${ }^{1}$ School of Medicine, International Peace Maternity and Child Health Hospital, Shanghai Jiao Tong University, \\ Shanghai 200030, China
}

Correspondence should be addressed to J Yang; Email: Dryangjing108@163.com or to be

WXu; Email: wangmingxu118@163.com

*(J Wang, F Wu and Q Xie contributed equally to this work)

\begin{abstract}
Bacteria and viruses activate the host innate immune response via Toll-like receptor (TLR)-involved signaling and potentially cause pregnancy failure. TLR7 and TLR9 respond to single-stranded RNA (a viral intermediate) and hypomethylated CpG DNA motifs (specific molecular constituents of bacteria) respectively. In this study, we treated murine RAW264.7 cells with R837, CpG1826, or a combination of the two. RT-PCR was performed to detect cytokines, TIr7, and TIr9. WT and nonobese diabetic murine embryo resorption models were established by i.p. injections of TLR7 and TLR9 ligands. Neutralizing antibodies and the IL1 $\beta$ and TNF $\alpha$ inhibitors were used. The specific inhibitors anakinra and etanercept effectively prevented TLR7 and TLR9 ligand-induced embryo loss. Notably, this effect was not observed in decidual NK cell-depleted mice. Our findings suggest that anakinra and etanercept may have potential for preventing TLR7 or TLR9 ligand-induced abortion in the presence of decidual NK cells.

Reproduction (2015) 149 377-384
\end{abstract}

\section{Introduction}

Considerable progress has been made in overcoming obstetric problems. However, preventing and reducing pregnancy failure remain as a major challenge. Approximately $10-15 \%$ of pregnant women undergo miscarriages that occur up to 24 weeks of gestation (Oliver \& Overton 2014). Many studies have attempted to study the etiopathogenesis of pregnancy failure, and microbial infection has emerged as an important cause of pregnancy failure in many of these studies. A large body of evidence indicates that inflammatory cytokines and chemokines are involved in bacterial and viral infections (Lin et al. 2009a, Ilievski \& Hirsch 2010, Li et al. 2012). Further data highlighting the significant relationship between Toll-like receptors (TLRs) and adverse pregnancy outcomes have drawn considerable attention (Filipovich et al. 2009, Lin et al. 2009b,c, 2014, Sun et al. 2013).

The innate immune system defends against invading microorganisms through pattern-recognition receptors such as TLRs (Takeda \& Akira 2004). TLRs can identify an extensive range of pathogen ligands including bacterial, viral, fungal, and protozoan components (Takeda \& Akira 2004, Kawai \& Akira 2005). TLRs are expressed by a wide range of immunocytes as well as nonimmune cells, and their expression is influenced by pathogens, cytokines, and outside stresses (Akira et al. 2006). Thus far, 13 TLR family members, distributed in different cellular compartments, have been discovered in mammals. TLR1, TLR2, TLR4, TLR5, and TLR6 are found mainly on the cell surface, while TLR3, TLR7, TLR8, and TLR9 are almost exclusively expressed within the cells (Kawai \& Akira 2005, Akira et al. 2006, Ilievski \& Hirsch 2010).

Each TLR has a specific ligand. During viral infection, TLR7 recognizes single-stranded RNA, which is the intermediate generated during viral replication (Heil et al. 2004). TLR9 mediates cellular responses to bacteria via their CpG motifs (Krieg 2002, Pedersen et al. 2005). Once TLR is stimulated by a ligand, downstream signaling events activate certain transcription factors to produce a series of inflammatory cytokines as the host defense response (Takeda \& Akira 2004).

Nonobese diabetic (NOD) mice have low fertility and are susceptible to TLR-induced embryo loss (Gautier et al. 2005, Lin et al. 2009f, Wang et al. 2009). Some studies have demonstrated that NOD mice exhibit insufficient numbers of NK cells migrating to the pregnant uterus (Wang et al. 2009, Sun et al. 2013, Lin et al. 2014). As decidual NK cells are considered to be a key cell subset beneficial for pregnancy success (Lin et al. 2006a, 2014, Wang et al. 2009, Sun et al. 2013), we used an NK cell-deficient NOD 
model and a WT control (Wang et al. 2009, Sun et al. 2013). In this study, we aimed to investigate the effects of combined stimulation of TLR7 and TLR9, in order to mimic a mixed infection with viruses and bacteria, both in vitro and in a murine pregnancy model.

\section{Materials and methods}

\section{Mice and ethics}

Female Balb/c, NK cell-deficient female NOD and male C57BL/6 mice (8-12 weeks of age; body weight, 18-22 g) were obtained from the Model Animal Center of Nanjing University (Nanjing, China). All the mice were housed in a pathogen-free facility. Balb/c $\times \mathrm{C} 57 \mathrm{BL} / 6$ and NOD $\times \mathrm{C} 57 \mathrm{BL} / 6$ mating combinations were established naturally, and the pregnant mice were treated to establish the induced embryo resorption models as described in the following sections. Samples were randomized as described previously (Lin et al. 2009d). The immunodeficiency of NOD mice was confirmed using the methods described previously (Lin et al. 2005, Rocha-Campos et al. 2006). All animal procedures were carried out in accordance with national animal care guidelines, and the study protocol was approved by the Institutional Animal Care and Use Committee (IACUC) of Wuhan University. All related data were approved for publication by the Institutional Review Board and Ethics Committee of Wuhan University. Each experimental group contained at least four mice. The day of vaginal plug appearance was designated as gestational day 0.5 (E0.5; Lin et al. 2006a, Sun et al. 2013).

\section{Cell culture}

The mouse macrophage cell line RAW264.7 (American Type Culture Collection, Manassas, VA, USA; TIB-71) was cultured in DMEM (high glucose; 11965-092; Gibco) supplemented with $10 \%$ fetal bovine serum (FBS), $1 \%$ streptomycin, and $1 \%$ penicillin in tissue culture flasks at $37^{\circ} \mathrm{C}$ in $5 \% \mathrm{CO}_{2}$ and $95 \%$ air. The cells were passaged every 2-3 days to ensure logarithmic phase growth. Before each experiment, the cells $\left(4 \times 10^{5}\right.$ cells/well) were plated in six-well plates in triplicate, incubated for $2 \mathrm{~h}$, and then treated with PBS, R837 (5 $\mu \mathrm{g} / \mathrm{ml})$, or CpG1826 $(10 \mu \mathrm{g} / \mathrm{ml})$ or both R837 and CpG1826 (both from Invivogen, San Diego, CA, USA). For sequential incubations, the medium was removed and the cells were washed three times with PBS before incubation with a second reagent. All tissue culture experiments were performed in triplicate and repeated three times (Lin et al. 2006a, llievski \& Hirsch 2010, Sun et al. 2013).

We used Trypan Blue dye exclusion to assess the viability of the cultured RAW 264.7 cells. The viability before plating for trial was $96 \%$. The viability at $5 \mathrm{~h}$ after plating was $94 \%$ for the control (medium), 92\% for R837, 93\% for $\mathrm{CpG}$, and $92 \%$ for R837 plus CpG. The post-plating cell viability did not significantly differ between the groups (Ilievski \& Hirsch 2010).

\section{RT-PCR analysis}

We evaluated the activation of TLR signaling pathways using RT-PCR system by measuring the relative quantity of transcripts such as interleukin 1 beta (I/1b), nitric oxide synthase 2 (Nos2), chemokine CCL5 (Ccl5), tumor necrosis factor alpha (Tnf), Tlr7, and TIr9 (Ilievski \& Hirsch 2010). At the end of the tissue culture experiment, the medium was aspirated, and the cells were washed once with PBS and lysed with TRIzol reagent (Invitrogen) to extract total RNA according to the manufacturer's protocol. All PCR primers and probes were purchased from Applied Biosystems (II1b, Mm00434228; Nos2, Mm00440485; Ccl5 (Rantes), Mm01302428; Tnf, Mm00443258; Tlr7, Mm00446590; TIr9, Mm00446193; and mouse glyceraldehyde 3-phosphate dehydrogenase (Gapdh; 203), 4452339E). TaqMan PCR reagent kits were used in accordance with the manufacturer's manual. Reactions occurred in a $10-\mu \mathrm{l}$ mixture containing $0.5 \mu \mathrm{l}$ of cDNA. Duplex RT-PCR was performed with one primer pair amplifying the gene of interest and the other amplifying an endogenous reference gene (Gapdh) in the same tube. The thermocycler parameters were $50^{\circ} \mathrm{C}$ for $2 \mathrm{~min}$, $95^{\circ} \mathrm{C}$ for $10 \mathrm{~min}$, and $30-45$ cycles at $95^{\circ} \mathrm{C}$ for $15 \mathrm{~s}$ and $60^{\circ} \mathrm{C}$ for $1 \mathrm{~min}$. Semiquantitative analysis of gene expression was performed using the comparative $C T$ method, normalizing the expression of the gene of interest to that of Gapdh. PCR assays were performed in duplicate for each of the triplicate tissue culture samples (Ilievski \& Hirsch 2010).

\section{In vivo treatment of pregnant mice}

R837 is a specific agonist for TLR7 (Heil et al. 2004, Lin et al. 2009b) and CpG is a specific agonist for TLR9 (Krieg 2002, Pedersen et al. 2005). The WTand NOD female mice impregnated by $\mathrm{C} 57 \mathrm{BL} / 6$ males received i.p. injections of $12.5 \mu \mathrm{g}$ R837 or $25 \mu \mathrm{g}$ of $\mathrm{CpG}$ oligodeoxynucleotide (CpG1826; Invivogen) on E6.5 (Thaxton et al. 2009, Sun et al. 2013).

For the neutralizing antibody experiment, mice were intraperitoneally administered $40 \mu \mathrm{g} /$ dam monoclonal anti-IL $1 \beta \mathrm{Ab}$ (B122; Biolegend, San Diego, CA, USA) and $250 \mu \mathrm{g} / \mathrm{dam}$ anti-TNF $\alpha$ Ab (Gr81-2626; BD Pharmingen, San Diego, CA, USA) on E5.5 and R837 and CpG injections on E6.5 (Thaxton et al. 2009, Sun et al. 2013).

Anakinra is a specific inhibitor for IL1 $\beta$ and etanercept is a specific inhibitor for TNF $\alpha$ (McCall et al. 2012). In the anakinra and etanercept experiments, the pregnant mice received i.p. injections of $100 \mu \mathrm{g} / \mathrm{dam}$ control $\mathrm{lgG}, 300 \mu \mathrm{g} / \mathrm{dam}$ anakinra, $100 \mu \mathrm{g} / \mathrm{dam}$ etanercept, or a combination of anakinra and etanercept at the mentioned doses (McCall et al. 2012, Johnston et al. 2014).

For the NK cell function experiment, NK cell depletion was performed on E4.5, E6.5, and E8.5 using 50 or $100 \mu \mathrm{l}$ of antiasialo GM1 (ASGM1), or an equal volume of nonimmune rabbit serum (Wako, Osaka, Japan) (Lin et al. 2006b, Thaxton et al. 2009, Sun et al. 2013).

Pregnant mice were killed on E10.5 and the embryo resorption rate $(\%)$ was calculated as follows: (number of resorbed embryos)/(total number of embryos) $\times 100$ (Lin et al. 2006a).

\section{Cell preparation}

Uterine mononuclear and granular cells were isolated by mincing and mechanical dispersion of whole E10.5 uteroplacental tissue in RPMI-1640 supplemented with 10\% FBS, 
penicillin/streptomycin, and L-glutamine. Single-cell suspensions from uterine horns were sifted through a $100-\mu \mathrm{m}$ cell strainer followed by density gradient separation using Fico/LiteLM (Atlanta Biologicals, Flowery Branch, GA, USA). These experiments were performed on the three layers obtained from Ficoll gradient separation to determine the layer in which the granulocytes accumulated. Granulocytes were found to get collected directly below the monocyte layer, and both layers were harvested together for further experiments (Thaxton et al. 2009, Sun et al. 2013).

\section{ELISA}

As no suitable NOS ELISA kit was available, serum IL1 $\beta$, CCL5, and TNF $\alpha$ cytokine levels were measured on E10.5. Briefly, peripheral blood was harvested from vena orbitalis (Lin et al. 2005), allowed to clot for $30 \mathrm{~min}$ at room temperature, spun at 8000 r.p.m. for $20 \mathrm{~min}$ at $4{ }^{\circ} \mathrm{C}$, and supernatants were collected and frozen for further analyses. IL1 $\beta$, CCL5, and TNF $\alpha$ were assayed using Quantikine ELISA kits (catalog number: SMLB00C, MMR00, and SMTA00B respectively; R\&D Systems, Minneapolis, MN, USA) and experiments were performed according to the manufacturer's instructions. Separate serum samples were collected from each experimental treatment group ( $n=6$ /group; Thaxton et al. 2009).

\section{Flow cytometry}

Antibodies specific for CD45 (30-F11) were purchased from BD Biosciences, Franklin Lakes, NJ, USA. FITC-conjugated Dolichos biflorus agglutinin (DBA)-lectin was purchased from SigmaAldrich. Isotype controls were established by staining of isotype control Abs to exclude false-positive cells (Lin et al. 2006a, 2009a).

\section{Statistical analysis}

Based on a normality test, the Student's $t$-test was used to evaluate differences in the gene expression between groups. For comparison of multiple variables, ANOVA was used. Differences were considered to be statistically significant when $P<0.05$ (Ilievski \& Hirsch 2010, Li et al. 2012).

\section{Results}

\section{Effect of R837 and CpG1826 on II1b and Tnf production}

The mouse macrophage cell line RAW 264.7 was used for our in vitro experiment. Both R837 and CpG1826 could synergistically enhance T/r7 and T/r9 activation and boost $I / 1 \mathrm{~b}$ and Tnf production in RAW 264.7 cells (Fig. 1). Challenge with either R837 or CpG1826 alone increased the $1 / 1 b$ (ninefold for R837 and eightfold for $\mathrm{CpG}$ ) and Tnf production (eightfold for R837 and tenfold for CpG) (Fig. 1). After challenge with R837 and CpG1826 together, the $I / 1 \mathrm{~b}$ and Tnf production was synergistically increased by 25 - and 33-fold, respectively, compared with the controls (Fig. 1A and D).
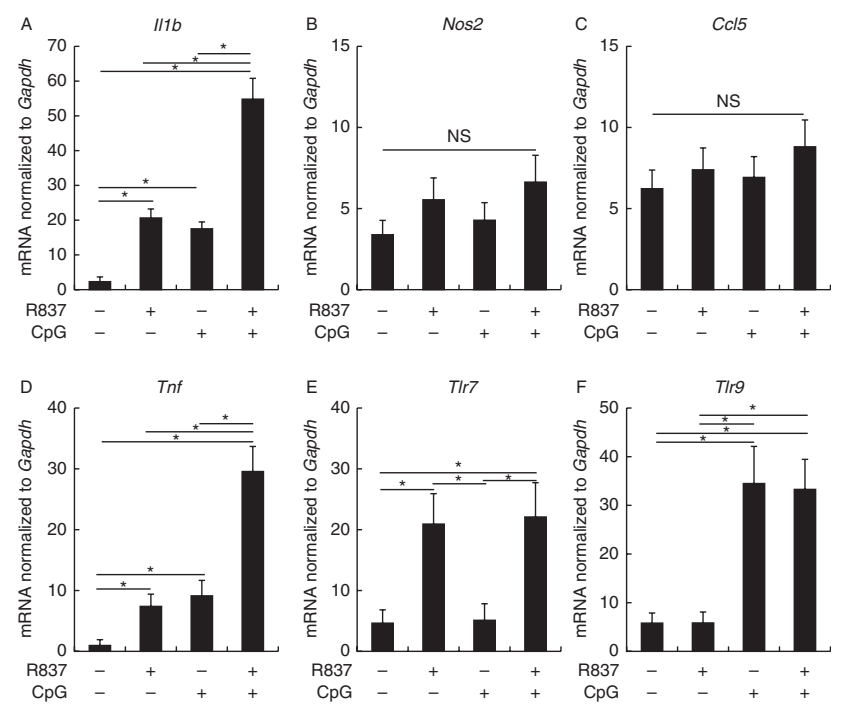

Figure 1 Synergistic effect of R837 and CpG on $/ / 1 \mathrm{~b}$ and Tnf production. RAW264.7 cells were stimulated with either PBS or R837 or CpG or a combination of R837 and CpG for $5 \mathrm{~h}$. RT-PCR was performed for IIIb (A), Nos2 (B), CCl5 (C), Tnf(D), Tlr7 (E), and Tlr9 (F), and the results were normalized to the housekeeping gene Gapdh. NS, not significant. $* P<0.01$.

No change was observed in TLR7- and TLR9-modulated Nos2 and Ccl5 production (Fig. $1 \mathrm{~B}$ and C). The TIr7 expression level significantly increased upon R837 stimulation, and the TIr9 expression was significantly increased upon CpG1826 stimulation. However, the TIr7 and Tlr9 levels showed no significant changes following combined treatment with R837 and CpG1826 (Fig. $1 \mathrm{E}$ and $\mathrm{F}$ ). This result implies that the synergistic effect of R837 and CpG on $/ 11 b$ and Tnf mRNA production depends on downstream events in the TLR7 and TLR9 signaling pathways.

\section{TLR7 or TLR9 engagement can prime cells for synergistic activation via the alternate ligand}

We examined whether the synergistic interaction between TLR7 and TLR9 requires presence of both the ligands. The RAW264.7 cells underwent sequential stimulation by incubation with R837 or CpG1826 for $5 \mathrm{~h}$, followed by washing and incubation for an additional $5 \mathrm{~h}$ with the alternate ligand. The results were compared with those obtained by exposing the cells to either one or both ligands for 5 and $10 \mathrm{~h}$. Sequential stimulation with either R837 followed by CpG1826 or vice versa induced the synergistic expression of both $/ 11 \mathrm{~b}$ and Tnf mRNAs, similar to that observed after simultaneous stimulation for Tnf mRNA, but displays a lower level than simultaneous stimulation for $I / 1 b$ (Fig. $2 A$ and D). Meanwhile, no such effect was observed in the modulation of Nos2 or Ccl5, which is the same as the result obtained with simultaneous stimulation (Fig. 2). 

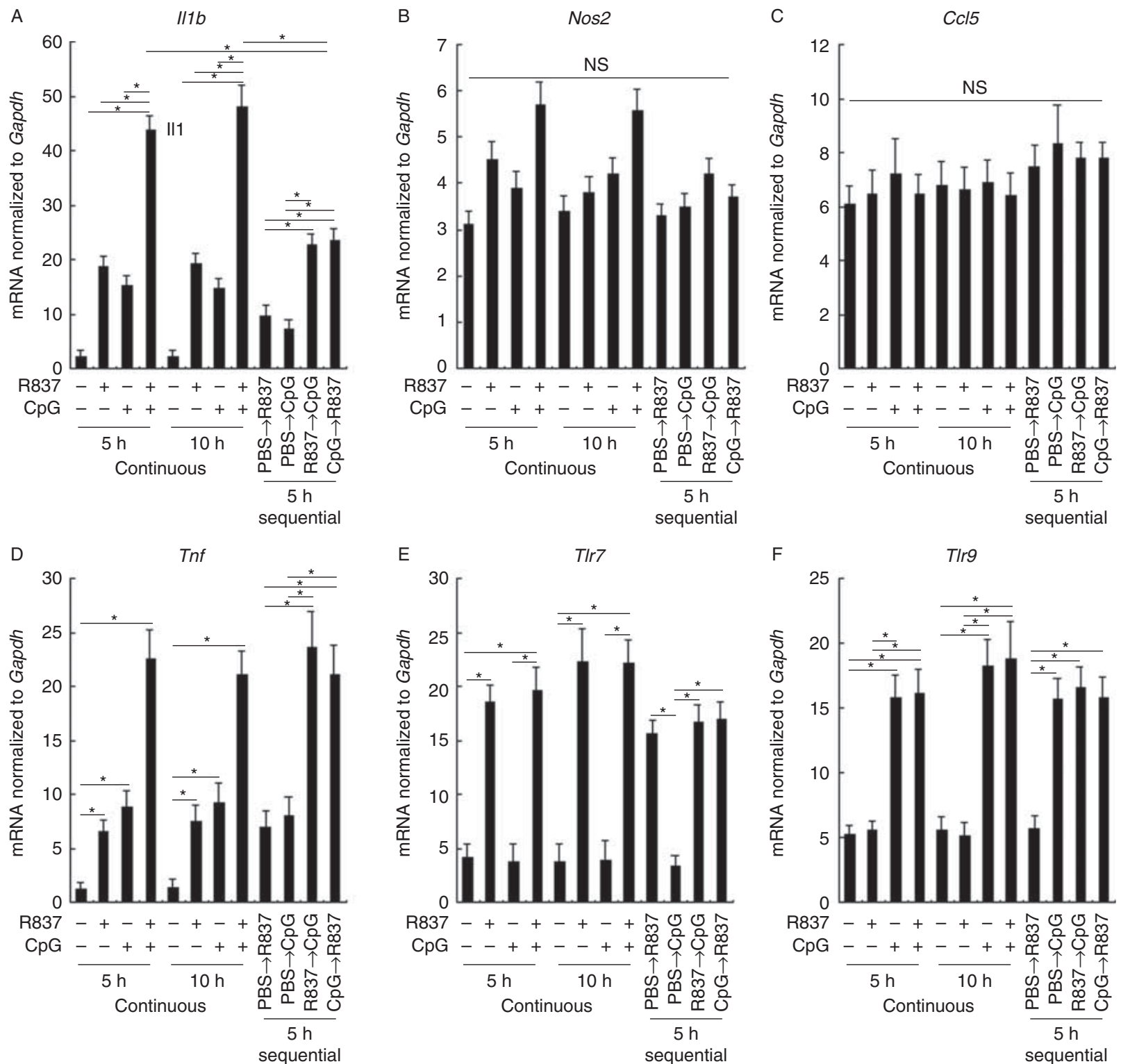

Figure 2 Effects of continuous and sequential R837 and CpG stimulations on TIr7 and TIr9 activation. RAW264.7 cells were treated in cell culture systems with either R837 or CpG or both R837 and CpG either simultaneously or sequentially for 5-10 h. For sequential incubations, the cultures were incubated with the first reagent for $5 \mathrm{~h}$, washed with PBS, and incubated for an additional $5 \mathrm{~h}$ with the second reagent. RT-PCR was performed using Gapdh as the control gene. NS, not significant. ${ }^{*} P<0.01$.

\section{Effects of IL1 $\beta$ and TNF $\alpha$ inhibitors on murine embryo resorption}

We used neutralizing Abs for IL1 $\beta$ and TNF $\alpha$ to examine their effects on R837- and CpG1826-induced embryo resorption in WT and NOD mice. We found that single antibodies against IL1 $\beta$ and TNF $\alpha$ could not decrease embryo resorption to a statistically supported level. Administration of combined antibodies for IL1 $\beta$ and TNF $\alpha$ significantly decreased the embryo resorption rate on the indicated doses $(45.0 \%$ vs $24.5 \%$ in WT and $70.5 \%$ vs $35.6 \%$ in NOD; $P<0.05$ for both; Fig. $3 \mathrm{~A}$ and $\mathrm{B})$.
Anakinra and etanercept were used to inhibit embryo resorption induced by R837 and CpG1826 (McCall et al. 2012). Using a single inhibitor significantly decreased the level of the TLR7 and TLR9 ligand-induced embryo resorption. Challenge with both inhibitors in combination (anakinra plus etanercept) further decreased the embryo resorption rate $(44.3 \%$ vs $6.6 \%$ in WT and $75.0 \%$ vs $17.5 \%$ in NOD; $P<0.01$ for both; Fig. 3C and D). In other words, almost completely abrogated R837 and CpG1826 induced embryo resorption increase $(6.6 \%$ vs $5.2 \%$ in WT and $17.5 \%$ vs $18.2 \%$ in NOD; Fig. 3C and D). 

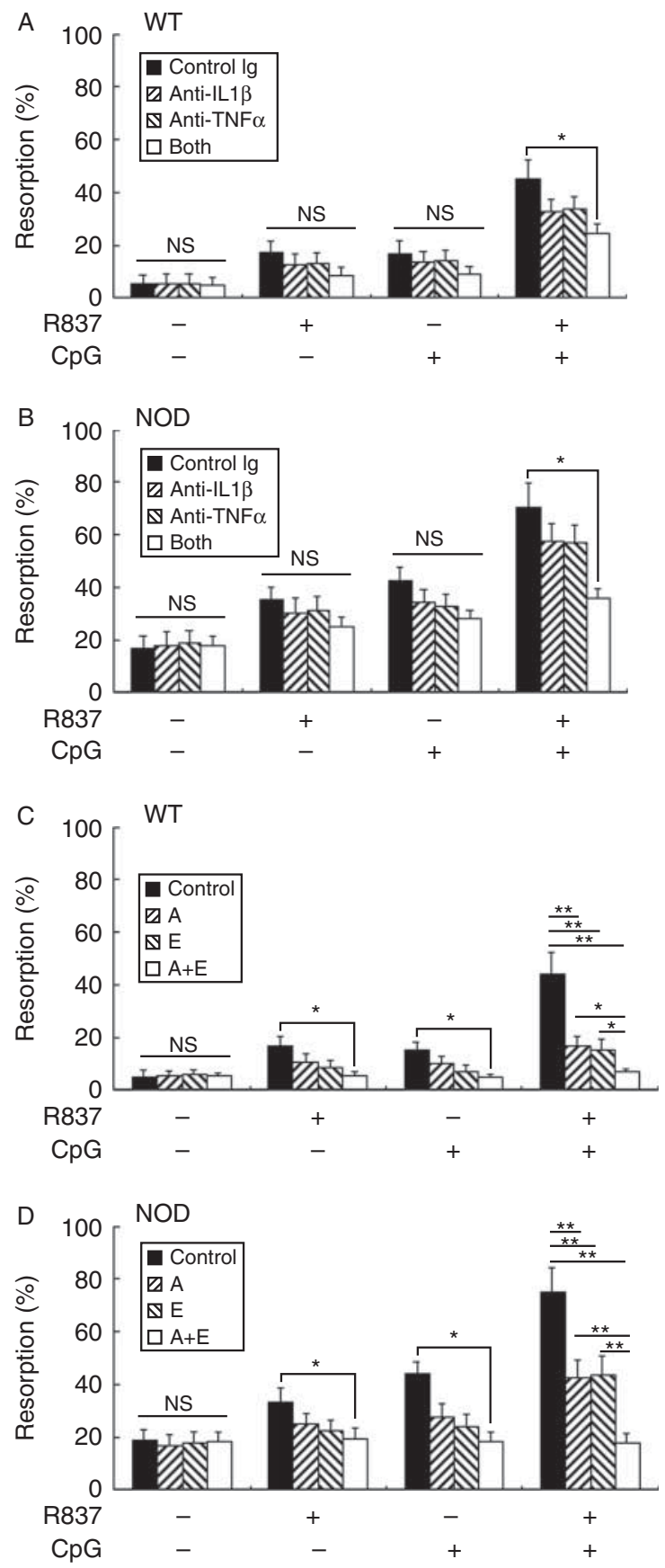

Figure 3 Effects of IL1 $\beta$ and TNF $\alpha$ inhibitors on murine embryo resorption. (A and B) Neutralizing antibodies against IL1 $\beta$ and TNF $\alpha$. $(C$ and $D)$ Anakinra $(A)$ and etanercept $(E)$ were used as the specific inhibitors for the IL1 $\beta$ and TNF $\alpha$ receptors respectively. These antibodies or inhibitors were used to prevent the R837 plus CpGinduced increase in murine embryo resorption. Single anti-IL1 $\beta$ or anti-TNF $\alpha$ antibodies did not change the embryo resorption rate. However, combined treatment of anti-IL1 $\beta$ and anti-TNF $\alpha$ antibodies significantly decreased the embryo resorption rate in both WT and NOD mice. In comparison, anakinra or etanercept when used individually at the indicated doses significantly decreased the R837and $\mathrm{CpG}$-induced increases in embryo resorption, while the combined inhibition using both inhibitors (anakinra plus etanercept or $\mathrm{A}+\mathrm{E}$ ) completely abrogated the R837- and CpG-induced increase in embryo resorption. NS, not significant. ${ }^{*} P<0.05$ and ${ }^{* *} P<0.01$.
Cytokines IL1 $\beta$ and TNF $\alpha$ but not CCL5 were increased by combined R837 and CpG stimulation

As examined by ELISA, serum IL1 $\beta(262.0 \pm 32.2 \mathrm{pg} / \mathrm{ml}$ vs $37.8 \pm 12.3 \mathrm{pg} / \mathrm{ml}$ in WT and $272.7 \pm 33.7 \mathrm{pg} / \mathrm{ml}$ vs $24.3 \pm 7.9 \mathrm{pg} / \mathrm{ml}$ in NOD; $P<0.01$ for both) and TNFa $(697.3 \pm 105.9 \mathrm{pg} / \mathrm{ml}$ vs $179.5 \pm 48.5 \mathrm{pg} / \mathrm{ml}$ in WT and $592.3 \pm 141.4 \mathrm{pg} / \mathrm{ml}$ vs $186.2 \pm 61.2 \mathrm{pg} / \mathrm{ml}$ in NOD; $P<0.01$ for both) cytokine levels were significantly increased upon combined R837 and CpG stimulation in both WT and NOD mice (Fig. 4A and C). In contrast, no such effect was found in chemokine CCL5 level (45.3 \pm $14.3 \mathrm{pg} / \mathrm{ml}$ vs $53.0 \pm 8.7 \mathrm{pg} / \mathrm{ml}$ in WT and $42.5 \pm$ $13.8 \mathrm{pg} / \mathrm{ml}$ vs $42.0 \pm 13.4 \mathrm{pg} / \mathrm{ml}$ in NOD; not statistically significant for both) (Fig. 4B). In addition, no significant difference was found in serum IL1 $\beta$ and TNF $\alpha$ cytokine levels between WT and NOD mice (Fig. 4).

\section{Anakinra and etanercept prevent R837- and CpG- induced embryo loss in an NK cell-dependent manner}

ASGM1 is a specific inhibitor of murine NK cells, which is commonly used to deplete decidual NK cells (Lin et al. $2006 b, 2009 d)$. In this study, combined treatment with anakinra and etanercept resulted in a potent decrease in the R837- and CpG-induced embryo resorption rate from 42.5 to $9.3 \%(P<0.01)$ in control mice, but this effect was diminished after ASGM1 treatment (from 50.0 to $37.5 \%, P>0.05)$. Similar results were obtained in NOD mice: combined treatment decreased the R837and CpG-induced resorption rate from 70.0 to $20.9 \%$ $(P<0.01)$; this effect was weakened in the ASGM1 group (100.0-60.0\%, $P>0.05$; Fig. 5). Our study indicated that combined treatment of anakinra and etanercept could prevent the R837- and CpG-induced embryo loss in an NK cell-dependent manner.

\section{Discussion}

Bacteria and viruses activate the innate immune responses of the host via TLR-mediated signaling. Infection by single or multiple pathogens may result in pregnancy failure. However, the mechanisms involved in this process remain largely unclear. TLR7 and TLR9 specifically respond to single-stranded RNA and $\mathrm{CpG}$, which represent viral and bacterial infections respectively. Our results indicate their synergic effect in mediating proinflammatory response, as combined stimulation with both the ligands resulted in a higher level of toxic cytokines than when a single ligand was used. Previous research exploring bacterial and viral coinfection has shown synergistic interaction between TLR2 and TLR3 (Ilievski \& Hirsch 2010). Furthermore, the additive effect of TLR3 and TLR7 cross-talk on immune cell function and their subsequent effects on pregnancy were explained (Lin et al. 2009b). In another study, TLR2 responded to many other TLR ligands, and its expression was upregulated significantly in response to different 

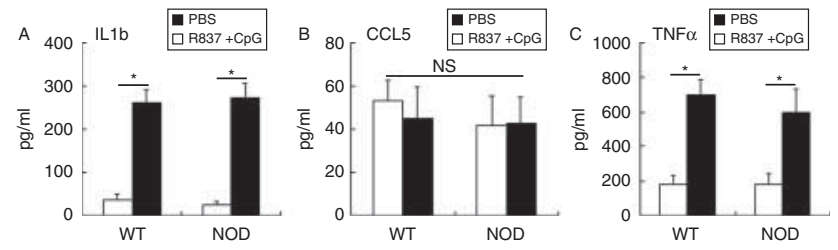

Figure 4 Cytokines IL1 $\beta$ and TNF $\alpha$ but not CCL5 were increased upon combined R837 and CpG stimulation. Pregnant mice were i.p. injected with R837 and CpG1826 combination on E6.5 and killed on E10.5 to detect the serum cytokine level by ELISA. (A) IL1 $\beta$. (B) CCL5. (C) TNF $\alpha$. IL1 $\beta$ and TNF $\alpha$ cytokine levels were significantly increased upon combined R837 and CpG stimulation, while no significant difference was found in the chemokine CCL5 level. NS, not significant. ${ }^{*} P<0.01$. $n=6$ per group.

microbial products (Nilsen et al. 2004). Therefore, there should be a greater focus on the prevention of multiple infections during pregnancy in clinical practice. In addition, the effect of occult infections may be underestimated for the superimposed effect between different kinds of pathogen.

NOD mice are much more sensitive to TLR7 and TLR9 ligands than WT mice (Sun et al. 2013, Lin et al. 2014). Inhibition of remnant NK cells in NOD mice will further increase the percentage of embryo loss (Lin et al. 2009d). In a previous study, NK cells in the pregnant uterus, featured as $\mathrm{CD} 16^{-} \mathrm{CD} 56^{\text {bright }}$, were found to have little cytolytic activity while producing high levels of cytokines. In contrast, CD $16^{+} \mathrm{CD} 56^{\mathrm{dim}}$ NK cells, which were predominately distributed in the peripheral blood, produced lower levels of cytokines but exhibited more cytotoxicity (Lin et al. 2009e). These findings indicate that the NK subsets in the pregnant uterus may play a supportive role in maintaining a successful pregnancy. In another study, transferring the $\mathrm{CD} 25^{+} \mathrm{CD}_{49 b^{+}}$subset of NK cells to NOD mice was found to improve pregnancy outcomes (Wang et al. 2009).

In this study, we found that costimulation of mouse RAW 264.7 cells with both R837 and CpG resulted in synergistic expression of mRNA for $\| 11 b$ and Tnf compared with either R837 or CpG alone. Then, sequential stimulation was performed by incubating RAW 264.7 cells with either R837 or CpG for $5 \mathrm{~h}$, followed by washing and incubation for an additional $5 \mathrm{~h}$ with the alternate ligand. These conditions were compared with both 5 and $10 \mathrm{~h}$ of simultaneous singleand double-ligand exposure. It showed that sequential stimulation with either R837 followed by CpG or vice versa induced synergistic expression of the same mRNAs for $I / 1 b$ and Tnf as observed in simultaneous stimulation settings. However, the level of increase was similar to simultaneous stimulation only for TnfmRNA, while the level of increase was significantly lower than simultaneous stimulation for $1 / 1 b$ mRNA. The mechanism for this is unclear. It implies a lower efficacy in $/ / 1 b$ mRNA induction in sequential stimulation conditions.

Anakinra and etanercept are specific receptor antagonists of IL1 $\beta$ and TNF $\alpha$ respectively (McCall et al. 2012).
Although they have been used clinically to treat inflammatory diseases like rheumatoid arthritis, little is known about their role in pregnancy (McCall et al. 2012). Neutralizing Abs slightly decreased the embryo resorption rate induced by R837 and CpG. However, anakinra and etanercept made the R837- and CpG-induced increase in embryo resorption to decline almost completely. These findings suggested that anakinra and etanercept may be useful to prevent pregnancy failure in cases of combined bacterial and viral infection (Chen et al. 1998, McCall et al. 2012, Guo et al. 2013).

When decidual NK cells were inhibited by the specific NK cell inhibitor ASGM1, anakinra and etanercept could not prevent embryo resorption. This indicates that the mechanism by which anakinra and etanercept prevent embryo loss depends on the presence of decidual NK cells (Wang et al. 2009).

However, we have not illustrated the mechanism of this interesting NK-dependent function in our study. Hanna et al. (2006) suggest that decidual NK cells, but not peripheral blood-derived NK subsets, regulate trophoblast invasion both in vitro and in vivo by production of the IL8 and interferon-inducible protein 10 chemokines, and that decidual NK cells are potent secretors of an array of angiogenic factors and induce vascular growth in the decidua. The finding implies that inhibition of decidual NK cells by ASGM1 itself may result in pregnancy failure by other mechanisms, such as impaired trophoblast invasion, interfered production of angiogenic factors, and aberrant vascular growth, instead of modulating IL1 $\beta$ - and TNF $\alpha$-involved inflammation.

Both IL1 $\beta$ and TNF $\alpha$ are important devastating inflammatory factors. IL1 $\beta$ regulates the expression of several genes such as $I / 6$ and Tnf through its receptor. $\mathrm{TNF} \alpha$, on the other hand, binds to cellular death domain and kills cells (McCall et al. 2012). IL1 $\beta$ and TNF $\alpha$ may work together to damage decidual NK cells. In this study, the serum levels of IL1 $\beta$ and TNF $\alpha$ cytokines were found to be markedly upregulated by combined R837 and CpG stimulation in pregnant mice on E10.5, in line with the RT-PCR results. Anakinra and etanercept may primarily inhibit the binding of these factors to decidual NK cells. Without these cells, anakinra and etanercept will not be able to function as described, leading to a high rate of pregnancy failure, as shown in our study.

Acute infection within the gestational compartment may be life threatening for pregnant women. Therefore, infection-induced abortion can be considered a strategy by which the host evacuates an infected body cavity, thus ensuring her own survival with retention of future reproductive potential (Thaxton et al. 2009, Ilievski \& Hirsch 2010).

The presence of viral pathogens within the gestational compartment and their effects are possibly underestimated in clinical practice because of limitations in viral culture and molecular methodology. Therefore, viral infection may potentially play a hitherto 
A

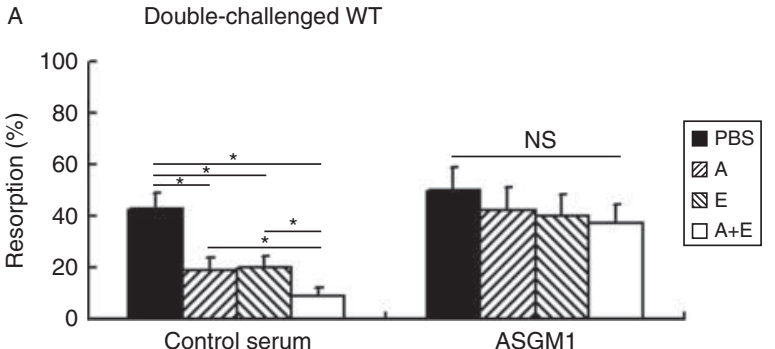

C

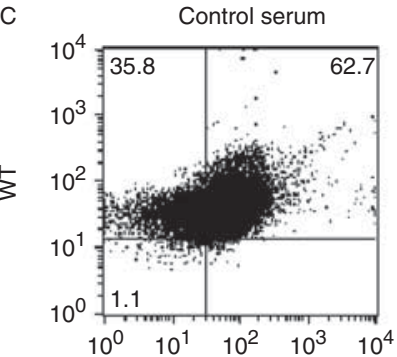

D

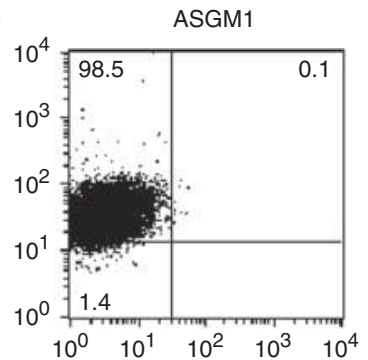

B

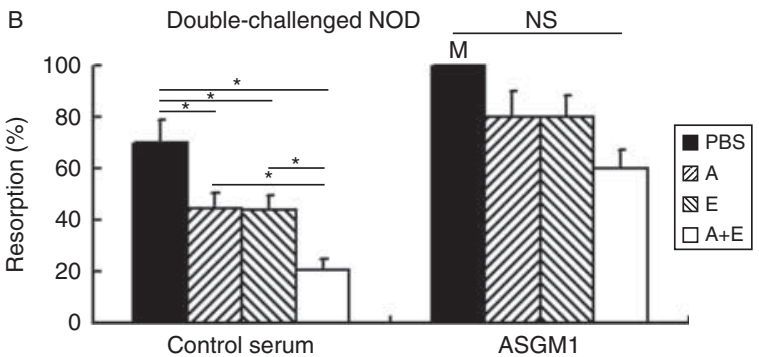

E

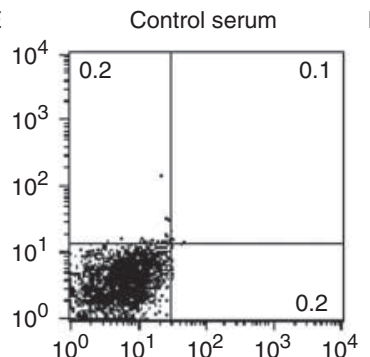

$\mathrm{F}$

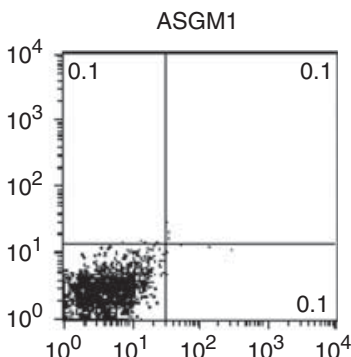

G

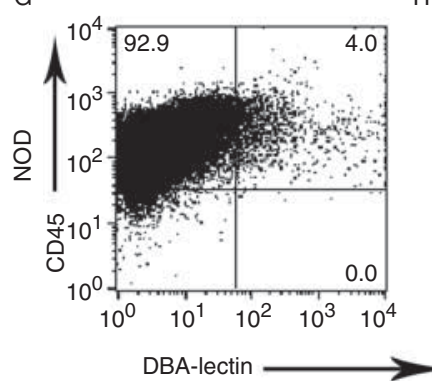

$\mathrm{H}$

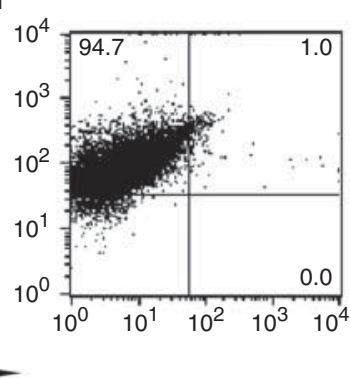

।

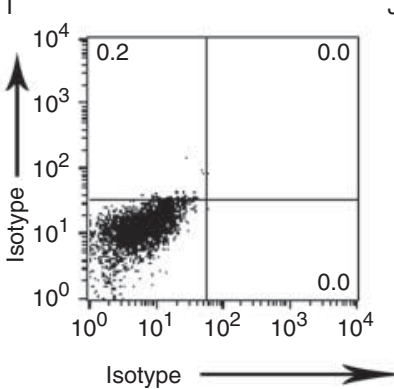

$\mathrm{J}$

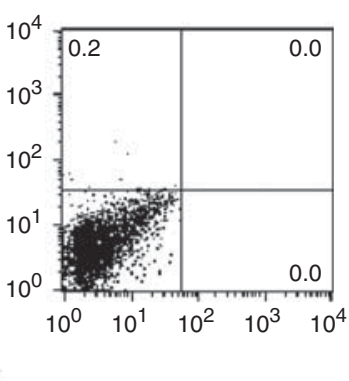

Figure 5 Anakinra and etanercept prevent R837- and CpG-induced embryo loss in an NK cell-dependent manner. (A and B) Double-challenged samples that were challenged with both R837 and CpG1826. ASGM1, anti-asialo GM1 antiserum. A, anakinra; E, etanercept; A+E, anakinra plus etanercept. When decidual NK cells were depleted by ASGM1 injection, administration with A, E, or A+E failed to inhibit the TLR7 and TLR9 ligand-induced increase in embryo resorption in both the WT and NOD mice. The effect of ASGM1 on decidual NK cell inhibition was confirmed in WT mice (C, D, E and F) and NOD mice (G, H, I and J) using flow cytometry. A small number of remnant NK cells were detected in some cases (H). DBA-lectin was used as a specific marker for murine decidual NK cells. M, Maximum embryo resorption rate (100\%) was observed under the indicated condition. NS, not significant. ${ }^{*} P<0.01$.

underappreciated role in pregnancy failure in culturenegative cases. Under the presence of subclinical viral infection, an acute and robust immune response may be triggered once there is an additional bacterial infection (Lin et al. 2009b, Ilievski \& Hirsch 2010).

In some cases, endogenously produced TLR ligands may influence the pregnancy outcome. At least two such candidate endogenous TLR ligands are potentially relevant to pregnancy outcomes, namely, low-molecularweight hyaluronan (a component of cervical extracellular matrix degraded during cervical ripening) and surfactant protein A (a protein produced by the maturing fetal lung that acts as a hormone signaling the onset of parturition in mice) (Condon et al. 2004, Jiang et al. 2005, Ilievski \& Hirsch 2010).

In conclusion, our findings reinforce the growing body of evidence demonstrating the key influence of TLRs on pregnancy outcomes. As $/ / 1 b$ and Tnf mRNAs were synergistically increased following stimulation by R837 and $\mathrm{CpG}$, the specific inhibitors anakinra and etanercept are potential candidate agents in the prevention of viral and bacterial causes of pregnancy failure.

\section{Declaration of interest}

The authors declare that there is no conflict of interest that could be perceived as prejudicing the impartiality of the research reported.

\section{Funding}

This work was supported partially by the National Basic Research Program of China (2013CB967404), the National Natural Science Foundation of China (81125004, 81350258, 81471456 and 81475457), the Fund for Outstanding Academic Leaders in Shanghai, China (12XD1406600 and 2013-049), and the Shanghai Jiao Tong University Medicine-Engineering Fund (YG2013ZD04 and YG2013MS68). 


\section{References}

Akira S, Uematsu S \& Takeuchi O 2006 Pathogen recognition and innate immunity. Cell 124 783-801. (doi:10.1016/j.cell.2006.02.015)

Chen Z, Colon I, Ortiz N, Callister M, Dong G, Pegram MY, Arosarena O, Strome S, Nicholson JC \& Van Waes C 1998 Effects of interleukin- $1 \alpha$, interleukin-1 receptor antagonist, and neutralizing antibody on proinflammatory cytokine expression by human squamous cell carcinoma lines. Cancer Research 58 3668-3676.

Condon JC, Jeyasuria P, Faust JM \& Mendelson CR 2004 Surfactant protein secreted by the maturing mouse fetal lung acts as a hormone that signals the initiation of parturition. PNAS 101 4978-4983. (doi:10.1073/pnas. 0401124101)

Filipovich Y, Lu SJ, Akira S \& Hirsch E 2009 The adaptor protein MyD88 is essential for $E$. coli-induced preterm delivery in mice. American Journal of Obstetrics and Gynecology 200 e91-e98. (doi:10.1016/j.ajog. 2008.08.038)

Gautier G, Humbert M, Deauvieau F, Scuiller M, Hiscott J, Bates EE, Trinchieri G, Caux C \& Garrone P 2005 A type I interferon autocrineparacrine loop is involved in Toll-like receptor-induced interleukin12p70 secretion by dendritic cells. Journal of Experimental Medicine 201 1435-1446. (doi:10.1084/jem.20041964)

Guo J, Gu N, Chen J, Shi T, Zhou Y, Rong Y, Zhou T, Yang W, Cui X \& Chen W 2013 Neutralization of interleukin- $1 \beta$ attenuates silica-induced lung inflammation and fibrosis in C57BL/6 mice. Archives of Toxicology 87 1963-1973. (doi:10.1007/s00204-013-1063-z)

Hanna J, Goldman-Wohl D, Hamani Y, Avraham I, Greenfield C, Natanson-Yaron S, Prus D, Cohen-Daniel L, Arnon TI, Manaster I et al. 2006 Decidual NK cells regulate key developmental processes at the human fetal-maternal interface. Nature Medicine 12 1065-1074. (doi:10.1038/nm1452)

Heil F, Hemmi $H$, Hochrein $H$, Ampenberger $F$, Kirschning C, Akira S, Lipford G, Wagner H \& Bauer S 2004 Species-specific recognition of single-stranded RNA via Toll-like receptor 7 and 8. Science 303 1526-1529. (doi:10.1126/science.1093620)

Ilievski V \& Hirsch E 2010 Synergy between viral and bacterial Toll-like receptors leads to amplification of inflammatory responses and preterm labor in the mouse. Biology of Reproduction 83 767-773. (doi:10.1095/ biolreprod.110.085464)

Jiang D, Liang J, Fan J, Yu S, Chen S, Luo Y, Prestwich GD, Mascarenhas MM, Garg HG, Quinn DA et al. 2005 Regulation of lung injury and repair by Toll-like receptors and hyaluronan. Nature Medicine 11 1173-1179. (doi:10.1038/nm1315)

Johnston WF, Salmon M, Pope NH, Meher A, Su G, Stone ML, Lu G, Owens GK, Upchurch GR Jr \& Ailawadi G 2014 Inhibition of interleukin-1 $\beta$ decreases aneurysm formation and progression in a novel model of thoracic aortic aneurysms. Circulation 130 S51-S59. (doi:10.1161/CIRCULATIONAHA.113.006800)

Kawai T \& Akira S 2005 Pathogen recognition with Toll-like receptors. Current Opinion in Immunology 17 338-344. (doi:10.1016/j.coi.2005. 02.007)

Krieg AM 2002 CpG motifs in bacterial DNA and their immune effects. Annual Review of Immunology 20 709-760. (doi:10.1146/annurev. immunol.20.100301.064842)

Li LP, Fang YC, Dong GF, Lin Y \& Saito S 2012 Depletion of invariant NKT cells reduces inflammation-induced preterm delivery in mice. Journal of Immunology 188 4681-4689. (doi:10.4049/jimmunol.1102628)

Lin Y, Chen Y, Zeng Y, Wang T \& Zeng S 2005 Lymphocyte phenotyping and NK cell activity analysis in pregnant NOD/SCID mice. Journal of Reproductive Immunology 68 39-51. (doi:10.1016/j.jri.2005.05.002)

Lin Y, Liang Z, Chen Y \& Zeng Y 2006a TLR3-involved modulation of pregnancy tolerance in double-stranded RNA-stimulated NOD/SCID mice. Journal of Immunology 176 4147-4154. (doi:10.4049/jimmunol. 176.7.4147)

Lin Y, Xie M, Chen Y, Di J \& Zeng Y 2006b Preterm delivery induced by LPS in syngeneically impregnated BALB/C and NOD/SCID mice. Journal of Reproductive Immunology 71 87-101. (doi:10.1016/j.jri.2006.01.005)
Lin $\mathbf{Y}, \mathbf{X u ~ L}$, Jin H, Zhong $\mathbf{Y}, \mathbf{D i} \mathbf{J}$ \& Lin Q 2009a CXCL12 enhances exogenous $\mathrm{CD} 4{ }^{+} \mathrm{CD} 25^{+} \mathrm{T}$ cell migration and prevents embryo loss in NOD mice. Fertility and Sterility 91 2687-2696. (doi:10.1016/j.fertnstert.2008.01.109)

Lin Y, Ren L, Wang W, Di J, Zeng S \& Saito S 2009b Effect of TLR3 and TLR7 activation in uterine NK cells from non-obese diabetic (NOD) mice. Journal of Reproductive Immunology 82 12-23. (doi:10.1016/j.jri. 2009.03.004)

Lin Y, Wang W, Jin H, Zhong Y, Di J, Zeng S \& Saito S 2009c Comparison of murine thymic stromal lymphopoietin- and polyinosinic polycytidylic acid-mediated placental dendritic cell activation. Journal of Reproductive Immunology 79 119-128. (doi:10.1016/j.jri.2008.10.001)

Lin Y, Wang H, Wang W, Zeng S, Zhong Y \& Li D-J 2009d Prevention of embryo loss in non-obese diabetic mice using adoptive ITGA2 ${ }^{+}$ISG $20^{+}$ natural killer-cell transfer. Reproduction 137 943-955. (doi:10.1530/ REP-08-0412)

Lin Y, Nakashima A, Shima T, Zhou X \& Saito S 2009e Toll-like receptor signaling in uterine natural killer cells - role in embryonic loss. Journal of Reproductive Immunology 83 95-100. (doi:10.1016/j.jri.2009.09.004)

Lin Y, Zhong Y, Saito S, Chen Y, Shen W, Di J \& Zeng S $2009 f$ Characterization of natural killer cells in nonobese diabetic/severely compromised immunodeficient mice during pregnancy. Fertility and Sterility 91 2676-2686. (doi:10.1016/j.fertnstert.2007.08.087)

Lin Y, Liu X, Shan B, Wu J, Sharma S \& Sun Y 2014 Prevention of CpGinduced pregnancy disruption by adoptive transfer of in vitro-induced regulatory T cells. PLOS ONE 9 e94702. (doi:10.1371/journal.pone. 0094702)

McCall M, Pawlick R, Kin T \& Shapiro AM 2012 Anakinra potentiates the protective effects of etanercept in transplantation of marginal mass human islets in immunodeficient mice. American Journal of Transplantation 12 322-329. (doi:10.1111/j.1600-6143.2011.03796.x)

Nilsen N, Nonstad U, Khan N, Knetter CF, Akira S, Sundan A, Espevik T \& Lien E 2004 Lipopolysaccharide and double-stranded RNA upregulate Toll-like receptor 2 independently of myeloid differentiation factor 88 . Journal of Biological Chemistry 279 39727-39735. (doi:10.1074/ jbc.M405027200)

Oliver A \& Overton C 2014 Diagnosis and management of miscarriage. Practitioner 258 25-28.

Pedersen G, Andresen L, Matthiessen MW, Rask-Madsen J \& Brynskov J 2005 Expression of Toll-like receptor 9 and response to bacterial CpG oligodeoxynucleotides in human intestinal epithelium. Clinical and Experimental Immunology 141 298-306. (doi:10.1111/j.1365-2249. 2005.02848.x)

Rocha-Campos AC, Melki R, Zhu R, Deruytter N, Damotte D, Dy M, Herbelin A \& Garchon HJ 2006 Genetic and functional analysis of the Nkt1 locus using congenic NOD mice: improved V $\alpha 14-N K T$ cell performance but failure to protect against type 1 diabetes. Diabetes $\mathbf{5 5}$ 1163-1170. (doi:10.2337/diabetes.55.04.06.db05-0908)

Sun Y, Qin X, Shan B, Wang W, Zhu Q, Sharma S, Wu J \& Lin Y 2013 Differential effects of the CpG-TLR9 axis on pregnancy outcome in nonobese diabetic mice and wild-type controls. Fertility and Sterility 99 1759-1767. (doi:10.1016/j.fertnstert.2013.01.121)

Takeda K \& Akira S 2004 TLR signaling pathways. Seminars in Immunology 16 3-9. (doi:10.1016/j.smim.2003.10.003)

Thaxton JE, Romero R \& Sharma S 2009 TLR9 activation coupled to IL-10 deficiency induces adverse pregnancy outcomes. Journal of Immunology 183 1144-1154. (doi:10.4049/jimmunol.0900788)

Wang W, Lin Y, Zeng S \& Li D-J 2009 Improvement of fertility with adoptive $\mathrm{CD} 25^{+}$natural killer cell transfer in sub-fertile NOD mice. Reproductive Biomedicine Online 18 95-103. (doi:10.1016/S1472-6483(10)60430-0)

Received 22 November 2014

First decision 19 December 2014

Revised manuscript received 25 December 2014

Accepted 19 January 2015 